\title{
Penggunaan Abu Batu untuk Mengurangi Agregat Pasir Alami pada Campuran Beton dengan Penambahan Zat Additive Type D
}

\author{
Use of Rock Ash to Reduce Natural Sand Aggregates in Concrete \\ Mixes by Adding Type D Additive Substances
}

\author{
Triaswati M.N. ${ }^{1, a)}$, Didik Harijanto ${ }^{1)}$, Boedi Wibowo ${ }^{1)}$ \& Wahyu Ismoyo ${ }^{1)}$ \\ ${ }^{1)}$ Departemen Teknik Infrastruktur Sipil, Fakultas Vokasi, (ITS). Surabaya. \\ Koresponden : ${ }^{a}$ triaswatimn@gmail.com.
}

\begin{abstract}
ABSTRAK
Industri beton di Indonesia sudah sangat maju dan berkembang. Maka penggunaan material konstruksi menjadi semakin meningkat. Dibutuhkan material lain sebagai pengganti agregat halus untuk pembuatan beton. Salah satu bahan yang dapat digunakan adalah abu batu yang berasal dari limbah industri batu belah. Penelitian ini dilakukan untuk mengetahui kuat tekan beton dengan variasi campuran (20\% abu batu, $80 \%$ pasir) dan (30\% abu batu, 70\% pasir). Dengan mutu beton Fc' 20 Mpa Fc' 25 Mpa, Fc' 40 Mpa dan penambahan zat additive type $D$. (water reducing and retarding), fungsi dari abu batu tersebut untuk mengurangi subtitusi agregat pasir alami pada campuran beton, dan fungsi dari zat additive type $\mathrm{D}$ tersebut yaitu untuk memperlambat waktu pengikatan dari semen. Penelitian menghasilkan kuat tekan beton dengan penggunaan abu batu $20 \%$ dan $30 \%$, hasil dari semua rencana mutu beton yang direncanakan pada umur 28 hari. Kuat tekan beton dengan menggunakan abu batu 20\%, pada Fc'20 Mpa mencapai 27,7 Mpa, untuk abu batu 30\%, pada Fc'20 Mpa mencapai 25,5 Mpa, unutk abu batu 20\%, dengan Fc' 25 Mpa mencapai 31,3 Mpa, unutk abu batu 30\%, dengan Fc' 25 Mpa mencapai 34 Mpa, unutk abu batu 20\%, dengan Fc' 40 Mpa mencapai 47,4 Mpa, unutk abu batu 30\%, dengan Fc'40 Mpa mencapai 47 Mpa. Pada semua variasi komposisi abu batu dengan semen penelitian ini, subtitusi agregat halus (pasir) dengan abu batu sangat baik digunakan untuk material campuran pada beton.
\end{abstract}

Kata Kunci : manajemen aset infrastruktur, perancangan infrastruktur, material, abu batu, zat addive type $\mathrm{D}$, mutu beton, kuat tekan.

\section{PENDAHULUAN}

Perkembangan Industri Beton di Indonesia sangatlah maju dan berkembang. semakin meningkatnya pembangunan di suatu negara maka penggunaan material konstruksi menjadi semakin meningkat. Beton merupakan campuran yang terdiri dari semen, agregat halus dan agregat kasar, air.

Prinsip Manajemen Aset Infrastruktur mengatakan bahwa suatu Infrastruktur harus dikelola dengan baik agar selalu bisa berfungsi dengan baik secara ekonomis disepanjang masa hidupnya (Suprayitno \& Soemitro 2018). Salah satu faktor yang harus dijaga untuk mencapai tujuan pengelolaan tersebut adalah penggunaan material konstruksi yang baik. Karena struktur beton praktis selalu ada disetiap infrastruktur di Indonesia, maka penelitian untuk menemukan kualitas beton yang lebih baik dan lebih tepat sesuai dengan kebutuhan harus selalu dilakukan. 
Perusahaan industri batu belah banyak dibutuhkan dalam kosntruksi, dari produksi batu belah dengan berbagai varian ukuran akan menghasilkan limbah yang disebut limbah abu batu. Abu batu sangatlah banyak dan kurang diminati sebagai bahan material.

Dari masalah tersebut limbah abu batu diangkat dalam penelitian ini untuk memberikan inovasi sebagai bahan tambah material konstruksi yang baik, berupa penggunaan material limbah abu batu sebagai subtitusi dari agregat pasir alami pada campuran beton dengan penambahan zat additive tipe $\mathrm{D}$.

Berdasarkan latar belakang tersebut, penelitian ini dapat dirumuskan sebagai berikut : Bagaimana pengaruh abu batu $20 \%$ dan $30 \%$ terhadap pasir alami pada campuran beton dengan penambahan zat additive tipe $\mathrm{D}$ ditinjau dari kuat tekan pada beton rencana.?

\section{METODA PENELITIAN}

\section{Batasan Penelitian}

Agar pembahasan penelitian ini terarah dan lebih focus, maka perlu pembatasan sebagai berikut :

1. Proporsi abu batu dengan pasir alami pada campuran beton $(20 \% \mathrm{AB}, 80 \% \mathrm{PS})$ dan (30\%AB, 70\%PS).

2. Kuat tekan beton yang direncankan mutu Fc' 20 Mpa (mutu minimum), Fc' $25 \mathrm{Mpa}$ (mutu medium) dan Fc' 40 Mpa (mutu high strength concrete).

3. Perencanaan mix desain menggunakan metode DOE (SNI 03-2834-2000).

4. Bahan tambah zat additive tipe D (water-reducing and retarding admixture) dengan dosis $0,30 \%$ dari berat semen. Produksi Pt. Varia Usaha beton.

5. Slump direncanakan $10 \pm 2 \mathrm{~cm}$ (SNI 1972-2008).

6. Tes kuat tekan beton umur 7,14 dan 28 hari (SNI 1974-2011).

7. Benda uji 9 sempel unutk setiap komposisi dan setiap uji mutu.

\section{Tempat dan Waktu Penelitian}

Penelitian dan test dilaksanakan di Laboratorium Beton, Jaminan Mutu dan Inovasi (JMI), PT. Semen Indonesia Beton (persero), Jln. Mayjen Sungkono, Kabupaten Gresik.

\section{Material Beton}

Bahan material beton yang digunakan dalam percobaan ini mengikuti beberapa ketentuan sebagai berikut.

- Semen Portland OPC tipe 1. Semen porland tersebut untuk pemakaian umum tanpa persyaratan khusus (SNI 15-2049-2004).

- Agregat kasar, agregat kasar yang diperoleh dari industri batu belah mempunyai ukuran antara $5 \mathrm{~s} / \mathrm{d} 40 \mathrm{~mm}$, syarat agregat kasar yang tertahan saringan ukuran 4,75mm.

- Agregat halus, agregat halus yang mempunyai ukuran butir 1,2mm dengan ukuran butir terkecil 0,075mm yang disebut slit, syarat agregat halus tertahan (PBI 1971).

- Air yang baik untuk campuran beton harus memenuhi persyaratan (SNI-S-04-1989-F).

- Zat additive tipe D Water Reducing and Retarding Admixtures adalah bahan tambah yang berfungsi ganda, yaitu untuk mengurangi jumlah air berapa persen dan untuk memperlambat proses pengikatan awal (ASTM C 494-C494M-05).

Selanjutnya, didalam penelitian tentang pemakaian abu batu dilakukan beberapa pemeriksaan penyelidikan bahan dan prosedur perawatan beton sebagai berikut.

1. Pemeriksaan dan penyelidikan bahan 
Pemeriksaan dan penyelidikan bahan material sesuai syarat dan ketentuan SNI. Seperti penyelidikan bahan semen, agregat kasar, agregat halus, agregat abu batu, dan air , yang terdiri dari tes kelembaban, berat jenis, air resapan, berat volume, kebersihan terhadap lumpur, kebersihan terhadap bahan organic, gradasi agregat, saringan modulus kehalusan.

2. Perawatan beton (Curing) Perawatang beton (Curing), Pada prinsipnya, tujuan perawatan adalah mencegah pengeringan yang bisa menyebabkan kehilangan air yang dibutuhkan untuk proses pengerasan beton atau mengurangi kebutuhan air selama proses hidrasi semen.

\section{DIAGRAM PENELITIAN}

Prosedur penelitian yang digunakan dari tahap awal, pengumpulan data, hingga pengolahan data dijelaskan dalam diagram alir berikut.

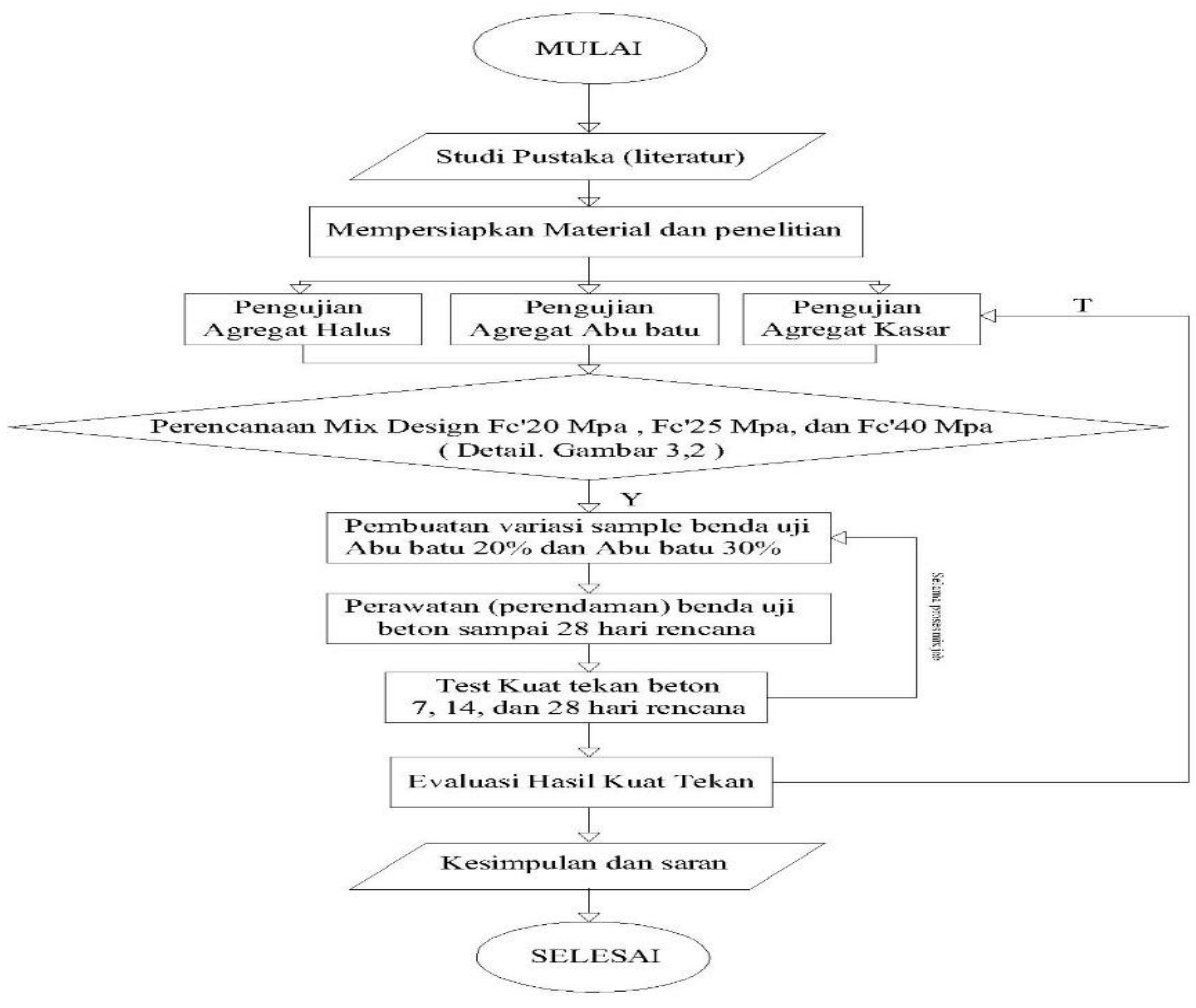

Gambar 1. Diagram Alir Penelitian 


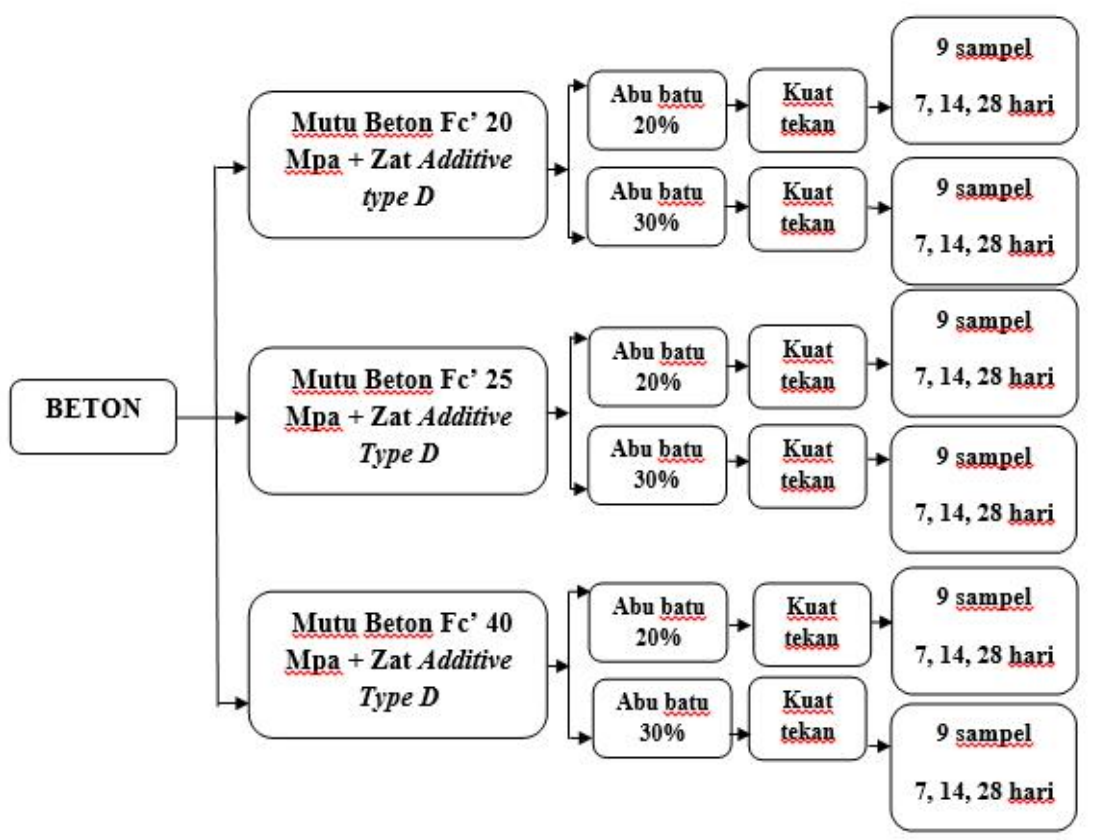

Gambar 2 Diagram Variasi Benda Uji

\section{HASIL PENELITIAN}

Penelitian ini menganalisis 6 Kombinasi Komposisi Tipe Semen dengan Prosentase Abu Batu. Tipe Semen yang digunakan adalah Semen Fc 20 Mpa, 25 Mpa dan 40 Mpa. Komposisi Abu Batu yang digunakan adalah untuk Komposisi 20\% dan 30\%. Hasil Kuat Tekan diukur untuk masing-masing Kombinasi Komposisi pada Beton Umur 7, 14, dan 28 hari. Hasil pengukuran Kuat Tekan Beton disampaikan dalam 2 kelompok Presentasi : dengan menggunakan Tabel dan Grafik sebagai berikut.

\section{Presentasi Hasil Penelitian dalam bentuk Tabel}

Hasil Percobaan dengan menggunakan Abu Batu 20\%

Kuat tekan rata - rata beton mutu Fc 20 Mpa dengan abu batu 20\% pada umur 7 hari sebesar Fc 16.6 Mpa, pada umur 14 hari kuat tekan beton naik menjadi Fc $21.5 \mathrm{Mpa}$, pada umur 28 hari kuat tekan beton naik menjadi Fc 27,7Mpa.

Tabel 1. Mutu Fc'20 Mpa dengan Abu Batu 20\%

\begin{tabular}{cccccc}
\hline \multirow{2}{*}{ No } & Berat beton & Beban tekan & Luas penampang & Hasil kuat tekan rata-rata & Umur \\
\cline { 2 - 6 } & $(\mathrm{Kg})$ & $\mathrm{P}(\mathrm{N})$ & $\mathrm{A}\left(\mathrm{mm}^{2}\right)$ & $\mathrm{P} / \mathrm{A}\left(\mathrm{N} / \mathrm{mm}^{2}\right)$ & (Hari) \\
\hline 1 & 12,9 & 293333 & 17662,5 & $16,6 \mathrm{Mpa}$ & 7 hari \\
2 & 12,76 & 380000 & 17662,5 & $21,5 \mathrm{Mpa}$ & 14 hari \\
3 & 12,76 & 490000 & 17662,5 & $27,7 \mathrm{Mpa}$ & 28 hari \\
\hline
\end{tabular}

Sumber: Hasil Penelitian, 2018

Kuat tekan rata - rata beton mutu Fc 25 Mpa dengan abu batu 20\% pada umur 7 hari sebesar Fc 17.5 Mpa, pada umur 14 hari kuat tekan beton naik menjadi Fc 26,2 Mpa, pada umur 28 hari kuat tekan beton naik menjadi Fc 31.3 Mpa. 
Tabel 2. Mutu Fc'25 Mpa dengan Abu Batu 20\%

\begin{tabular}{cccccc}
\hline No & Berat beton & Beban & Luas & Hasil kuat tekan rata- & Umur \\
\cline { 2 - 6 } & $(\mathrm{Kg})$ & $\mathrm{P}(\mathrm{N})$ & $\mathrm{A}\left(\mathrm{mm}^{2}\right)$ & $\mathrm{P} / \mathrm{A}\left(\mathrm{N} / \mathrm{mm}^{2}\right)$ & (Hari) \\
\hline 1 & 12,63 & 310000 & 17662,5 & $17,5 \mathrm{Mpa}$ & 7 hari \\
2 & 12,76 & 463333 & 17662,5 & $26,2 \mathrm{Mpa}$ & 14 hari \\
3 & 12,73 & 553333 & 17662,5 & $31,3 \mathrm{Mpa}$ & 28 hari \\
\hline
\end{tabular}

Sumber: Hasil Penelitian, 2018)

Kuat tekan rata - rata beton mutu Fe 40 Mpa dengan abu batu 20\% pada umur 7 hari sebesar Fc $24 \mathrm{Mpa}$, pada umur 14 hari kuat tekan beton naik menjadi Fc $39.3 \mathrm{Mpa}$, pada umur 28 hari kuat tekan beton naik menjadi Fc 47.4 Mpa.

Tabel 3. Mutu Fc'40 Mpa dengan Abu Batu 20\%

\begin{tabular}{cccccc}
\hline No & Berat beton & Beban & Luas & Hasil kuat tekan rata- & Umur \\
\cline { 2 - 6 } & $(\mathrm{Kg})$ & $\mathrm{P}(\mathrm{N})$ & $\mathrm{A}\left(\mathrm{mm}^{2}\right)$ & $\mathrm{P} / \mathrm{A}\left(\mathrm{N} / \mathrm{mm}^{2}\right)$ & (Hari) \\
\hline 1 & 12,73 & 423333 & 17662,5 & $24,0 \mathrm{Mpa}$ & 7 hari \\
2 & 12,73 & 693333 & 17662,5 & $39,3 \mathrm{Mpa}$ & 14 hari \\
3 & 12,76 & 836666 & 17662,5 & $47,4 \mathrm{Mpa}$ & 28 hari \\
\hline
\end{tabular}

Sumber: Hasil Penelitian, 2018

Hasil Percobaan dengan menggunakan Abu Batu 30\%

Kuat tekan rata - rata beton mutu Fc 20 Mpa dengan abu batu 30\% pada umur 7 hari sebesar Fc $17 \mathrm{Mpa}$, pada umur 14 hari kuat tekan beton naik menjadi Fc 21.1 Mpa, pada umur 28 hari kuat tekan beton naik menjadi Fc 25.5Mpa.

Tabel 4. Mutu Fc'20 Mpa dengan abu batu 30\%

\begin{tabular}{cccccc}
\hline \multirow{2}{*}{ No } & Berat beton & Beban tekan & Luas penampang & Hasil kuat tekan rata-rata & Umur beton \\
\cline { 2 - 6 } & $(\mathrm{Kg})$ & $\mathrm{P}(\mathrm{N})$ & $\mathrm{A}\left(\mathrm{mm}^{2}\right)$ & $\mathrm{P} / \mathrm{A}\left(\mathrm{N} / \mathrm{mm}^{2}\right)$ & (Hari) \\
\hline 1 & 12,73 & 300000 & 17662,5 & $17 \mathrm{Mpa}$ & 7 hari \\
2 & 12,76 & 373333 & 17662,5 & $21,1 \mathrm{Mpa}$ & 14 hari \\
3 & 12,73 & 450000 & 17662,5 & $25,5 \mathrm{Mpa}$ & 28 hari \\
\hline
\end{tabular}

Sumber: Hasil Penelitian, 2018

Kuat tekan rata - rata beton mutu Fc' 25 Mpa dengan abu batu 30\% pada umur 7 hari sebesar Fc'20.8 Mpa, pada umur 14 hari kuat tekan beton naik menjadi Fc' $31.1 \mathrm{Mpa}$, pada umur 28 hari kuat tekan beton naik menjadi Fc 34.0Mpa. 
Tabel 5. Mutu Fc'25 Mpa dengan abu batu 30\%

\begin{tabular}{cccccc}
\hline \multirow{2}{*}{ No } & Berat & Beban tekan & Luas penampang & Hasil kuat tekan rata-rata & Umur beton \\
\cline { 2 - 6 } & $(\mathrm{Kg})$ & $\mathrm{P}(\mathrm{N})$ & $\mathrm{A}\left(\mathrm{mm}^{2}\right)$ & $\mathrm{P} / \mathrm{A}\left(\mathrm{N} / \mathrm{mm}^{2}\right)$ & (Hari) \\
\hline 1 & 12,56 & 366666 & 17662,5 & $20,8 \mathrm{Mpa}$ & 7 hari \\
2 & 12,73 & 550000 & 17662,5 & $31,1 \mathrm{Mpa}$ & 14 hari \\
3 & 12,73 & 600000 & 17662,5 & $34,0 \mathrm{Mpa}$ & 28 hari \\
\hline
\end{tabular}

Sumber: Hasil Penelitian, 2018

Kuat tekan rata - rata beton mutu Fc' 40 Mpa dengan abu batu 30\% pada umur 7 hari sebesar atau Fc'31.3 Mpa, pada umur 14 hari kuat tekan beton naik menjadi Fc' 39,4 Mpa, pada umur 28 hari kuat tekan beton naik menjadi Fc' 47 Mpa.

Tabel 6. Mutu Fc'40 Mpa dengan abu batu 30\%

\begin{tabular}{cccccc}
\hline No & Berat beton & Beban tekan & Luas penampang & $\begin{array}{c}\text { Hasil Kuat Tekan Beton } \\
\text { Rata rata }\end{array}$ & $\begin{array}{c}\text { Umur } \\
\text { beton }\end{array}$ \\
\cline { 2 - 6 } & $(\mathrm{Kg})$ & $\mathrm{P}(\mathrm{N})$ & $\mathrm{A}\left(\mathrm{mm}^{2}\right)$ & $\mathrm{P} / \mathrm{A}\left(\mathrm{N} / \mathrm{mm}^{2}\right)$ & (Hari) \\
\hline 1 & 12,66 & 553333 & 17662,5 & $31,3 \mathrm{Mpa}$ & 7 hari \\
2 & 12,6 & 696666 & 17662,5 & $39,4 \mathrm{Mpa}$ & 14 hari \\
3 & 12,73 & 830000 & 17662,5 & $47,0 \mathrm{Mpa}$ & 28 hari \\
\hline
\end{tabular}

Sumber: Hasil Penelitian, 2018

\section{Presentasi Hasil Penelitian dalam bentuk Grafik}

Demi kemudahan dalam memahami Hasil Penelitian, hasil percobaan disampaikan dalm bentuk 3 buah Grafik Variasi Kuat Tekan sebagai berikut.

Hasil Percobaan menggunakan Semen Mutu Fc' 20 Mpa.

Percobaan pertama menggunakan Semen Fc' 20 Mpa dengan menggunakan 2 variasi Kandungan Abu Batu 20\% dan 30\%. Kuat tekan beton umur 28 hari, abu batu 20\% sebesar 27,74 Mpa dan abu batu 30\% sebesar 25,5 Mpa. Pada umur rencana kuat tekan beton 28 hari abu batu 20\% dan abu batu 30\% sudah melebih kuat tekan rencana yang direncanakan.

Kuat Tekan Beton pada umur 28 hari pada Mutu Semen Fc'20 Mpa dengan menggunakan Abu Batu 20\% lebih tinggi dari pada Kuat Tekan Beton dengan menggunakan Abu Batu 30\% . Kuat Tekan Beton untuk Abu Batu 20\% adalah sebesar 27,74 Mpa. 


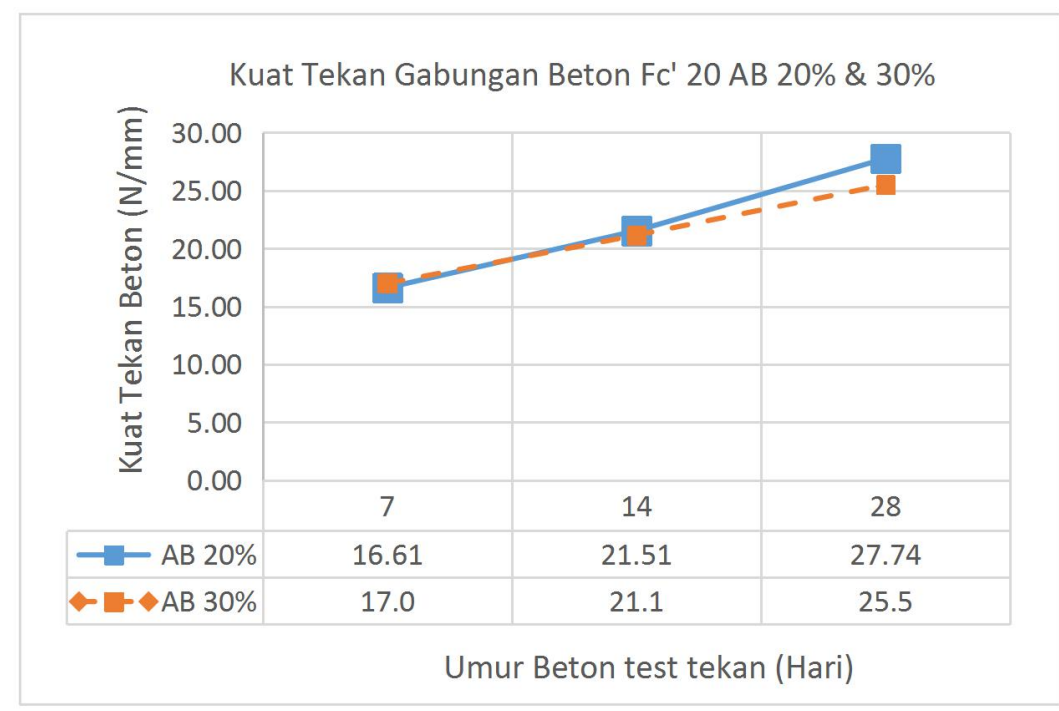

Gambar 3. Perbandingan Kuat Tekan Beton Mutu Fc"20 AB20\% dan AB30\%

Hasil Percobaan menggunakan Semen Mutu Fc' 25 Mpa

Percobaan kedua menggunakan beton Fc' $25 \mathrm{Mpa}$ dan dengan abu batu 20\% dan abu batu 30\% . Kuat Tekan Beton pada umur 28 hari untuk abu batu 20\% sebesar 31,33 Mpa dan untuk abu batu 30\% sebesar $34 \mathrm{Mpa}$. Pada umur rencana kuat tekan beton 28 hari abu batu $20 \%$ dan abu batu $30 \%$ sudah melebih kuat tekan rencana yang direncanakan.

Hasil percobaan pada umur 28 hari menunjukkan bahwa Kuat Tekan Beton untuk Abu Batu 20\% lebih tinggi dari pada untuk Abu Batu 30\%, dengan hasil kuat tekan beton sebesar $34 \mathrm{Mpa}$.

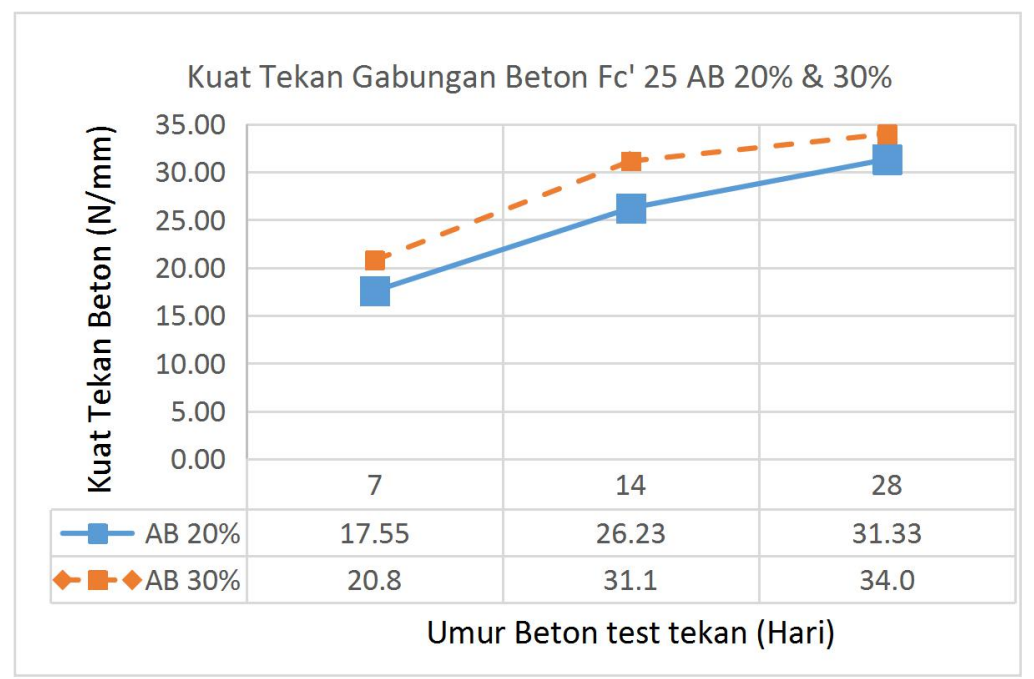

Gambar 4. Perbandingan Kuat Tekan Beton Mutu Fc'25 dengan AB20\% dan AB30\%

Hasil Percobaan menggunakan Semen Mutu Fc' 40 Mpa

Percobaan ketiga menggunakan Mutu Semen Fc' 40 Mpa dengan Abu Batu 20\% dan $30 \%$. Kuat Tekan Beton umur 28 hari, abu batu 20\% sebesar 47,4 Mpa dan abu batu 30\% sebesar $37 \mathrm{Mpa}$. Pada umur rencana kuat tekan beton 28 hari abu batu 20\% dan abu batu 30\% sudah melebih kuat tekan rencana yang direncanakan.

Hasil percobaan pada umur 28 hari menunjukkan bahwa Kuat Tekan Beton dengan Abu Batu 20\% lebih tinggi dari pada dengan menggunakan Abu Batu 30\%. Kuat Tekan Beton unutk Abu Btu 20\% adalah sebesar 47,4 Mpa. 


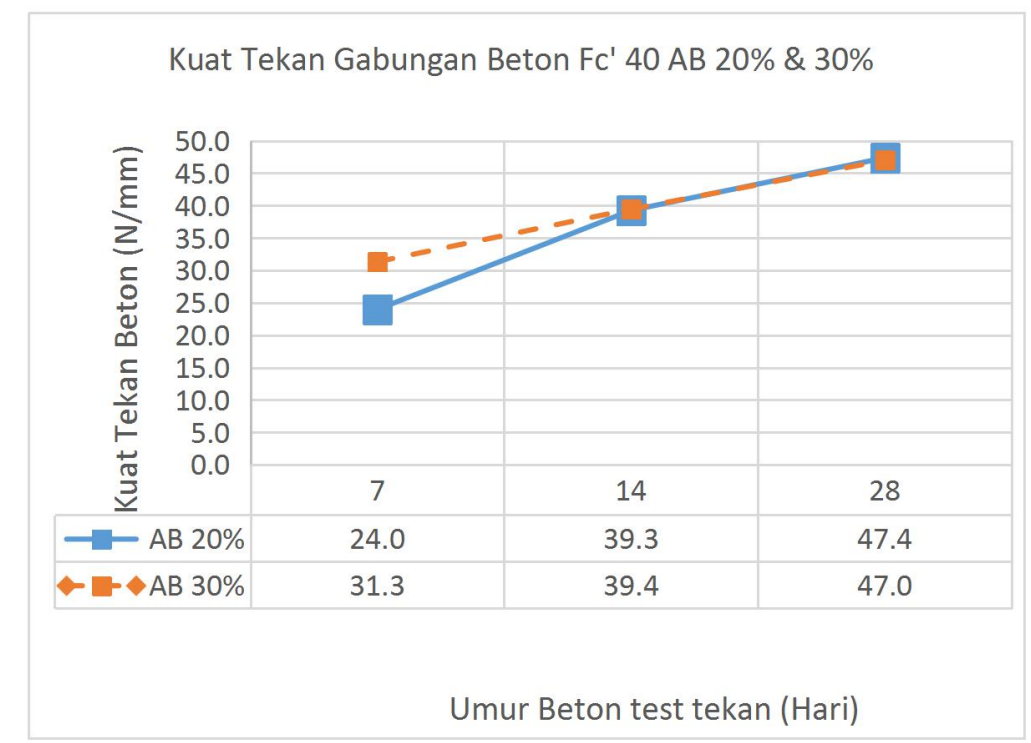

Gambar 5. Perbandingan Kuat Tekan Beton Mutu Fc40’ dengan AB20\% dan AB30\%

\section{KESIMPULAN DAN SARAN}

\section{Kesimpulan}

Penelitian ini telah berhasil diselesaikan dengan baik dan menghasilkan dua kesimpulan utama tentang Kuat Tekan Beton untuk Komposisi abu batu 20\% dan 30\%. Kesimpulan utama disampaikan sebagai berikut.

Komposisi abu batu $20 \%$ dengan zat additive tipe D

- Fc' $20 \mathrm{Mpa}$, hasil kuat tekan beton umur 28 hari sebesar Fc' 27,7 Mpa.

- Fc' 25 Mpa, hasil kuat tekan beton umur 28 hari sebesar Fc' 31,33 Mpa.

- Fc' 40 Mpa, hasil kuat tekan beton umur 28 hari sebesar Fc' 47,4 Mpa.

Komposisi abu batu 30\% dengan zat additive tipe D

- Fc' 20 Mpa, hasil kuat tekan beton umur 28 hari sebesar Fc'25,5 Mpa.

- Fc' 25 Mpa, hasil kuat tekan beton umur 28 hari sebesar Fc' 34 Mpa.

- Fc' 40 Mpa, hasil kuat tekan beton umur 28 hari sebesar Fc' 47 Mpa.

\section{Saran}

Dalam studi ini, abu batu sebagai pengganti pasir sangat baik digunakan sebagai material bahan tambah pada campuran beton dengan subtitusi penganti pasir alami.

Agar diperoleh sampel yang baik perlu diperhatikan pada saat mengoptimalkan proporsi abu batu dengan pasir, dan setiap proses dari penyelidikan material dan, penggunaan bahan tambah zat additive tipe $\mathrm{D}$, harus sesuai prosedur pembuatan beton, karena apabila tidak sesuai prosedur yang baik maka sampel akan sangat mempengaruhi kekuatan yang akan direncanakan.

Subtitusi campuran abu batu untuk mengurangi agregat pasir alami yang baik yaitu (20\% abu batu, $80 \%$ pasir alami) dan (30\% abu batu dan $70 \%$ pasir alami), dengan ketentuan abu batu harus di cuci untuk menggurangi kadar lumpur yang sangat tinggi diharuskan sesuai standar agregat tidak lebih dari 5\%. 


\section{DAFTAR PUSTAKA}

ASTM C 494-C494M-05. ASTM C 494-C494M-05 - Standart specification admixture chemical for concrete.

PBI 1971. Peraturan Beton Bertulang Indonesia 1971. Lembaga Penyelidikan Masalah Bangunan. Bandung.

SNI 63-2834-2000. Standart Nasional Indonesia (SNI) 03-2834-2000 - Tata Cara Pembuatan Campuran Beton Normal.

SNI 15-2049-2004. Standart Nasional Indonesia (SNI) SNI 15-2049-2004 - Semen Portland.

SNI 1972-2008. Standart Nasional Indonesia (SNI) 1972-2008 - Tata Cara slump beton.

SNI 1974-2011. Standart Nasional Indonesia (SNI) 1974-2011 - Cara uji kuat tekan beton dengan benda uji silinder.

SNI S-04-1989-F. Standart Nasional Indonesia (SNI) S-04-1989-F - Spesifikasi Bahan Bangunan Bagian Bawah.

Suprayitno, H. \& Soemitro, R.A.A. (2018). "Prelimanery Reflexion on Basic Principle of Infrastructure Asset Management”. Jurnal Manajemen Aset Infrastruktur, Vol. 2, No. 1, Maret 2018, Hal : 1-9. 
(e)ISSN 2615-1847 (p)ISSN 2615-1839

Jurnal Manajemen Aset Infrastruktur \& Fasilitas - Vol. 3, Edisi Khusus 2, Juni 2019 